Article

\title{
Graphene Quantum Dots and Enzyme-Coupled Biosensor for Highly Sensitive Determination of Hydrogen Peroxide and Glucose
}

\author{
Bingdi Wang ${ }^{1,2}$, Jing Shen ${ }^{1}$, Yanjun Huang ${ }^{1}$, Zhenning Liu ${ }^{2}$ and Hong Zhuang ${ }^{1, *}$ \\ 1 College of Food Science and Engineering, Jilin University, Changchun, Jilin 130062, China; \\ wangbd16@mails.jlu.edu.cn (B.W.); shenjing9915@163.com (J.S.); huangyanj@jlu.edu.cn (Y.H.) \\ 2 Key Laboratory of Bionic Engineering (Ministry of Education), College of Biological and Agricultural \\ Engineering, Jilin University, Changchun, Jilin 130022, China; liu_zhenning@jlu.edu.cn \\ * Correspondence: zhuanghong@jlu.edu.cn; Tel.: +86-139-4410-2716
}

Received: 7 May 2018 ; Accepted: 28 May 2018 ; Published: 7 June 2018

\begin{abstract}
In this paper, a simple and specific graphene quantum dots (GQDs)-based fluorescent biosensor adopted for the determination of glucose based on the combination of the enzyme-coupled method and fluorescence quenching mechanism is demonstrated. Glucose was oxidized by the enzyme glucose oxidase (GOx), forming hydrogen peroxide $\left(\mathrm{H}_{2} \mathrm{O}_{2}\right)$ via the catalysis by horseradish peroxidase (HRP). $\mathrm{H}_{2} \mathrm{O}_{2}$ was then employed to oxidize phenol to quinone, which led to effective quenching effect in the GQDs-GOx-HRP-phenol system. By optimizing the reaction conditions of the GQDs-enzyme system, a linear relationship between the concentration of glucose and the fluorescence intensity over a range of $0.2-10 \mu \mathrm{mol} / \mathrm{L}$ was obtained. The limit of detection for glucose is $0.08 \mu \mathrm{mol} / \mathrm{L}$. The present biosensor for the determination of glucose showed satisfactory reproducibility and accuracy in human serum samples. Since the enzymes have high specificity and unique affinity to the certain substance, the enzyme-coupled system promises a sensitive way for further detection of those chemicals which could be oxidized by enzymes and generated $\mathrm{H}_{2} \mathrm{O}_{2}$ or glucose. GQDs and other fluorescent materials coupled with several enzymes can be applied to extensive sensing field.
\end{abstract}

Keywords: graphene quantum dots; bio-enzyme detection; glucose; enzyme-coupled biosensor; quenching method

\section{Introduction}

Glucose is a basic and widely-used monosaccharide that can be found easily in both human bodies and other species. Glucose acts as the raw material and the intermediate product of respiration and metabolism, and an unbalanced glucose level in the human body can lead to such disease as diabetes which is considered a principal health problem that negatively affects millions of people in the world [1,2]. Glucose monitoring and diabetes diagnostic have been continuous concerns among the public. The fast and accurate monitoring of glucose level, mainly in blood, is necessary for diagnostic and treatment [3,4]. In recent years, various kinds of methods have been applied in glucose quantitative analysis in different samples, including electrometric [5], voltammetric [6], colorimetric [7] and fluorimetric detection [8,9]. Fluorescence detection is a current research interest in analyzing food [10], diagnosing of diabetes [11,12], etc. Because of the convenient implementation and high sensitivity, several types of bio-probes have been made using enzymes and some fluorescent material for fast and deep sensing detection [13,14].

Enzymes and coenzymes have been extensively used in sensing system owing to their high activity and specificity, acting as biosensors in the electrochemical and optical area $[15,16]$. They are capable of changing function and structure, thus frequently modified onto the sensor or added in the solution 
to accelerate or change the process $[17,18]$. Compared with the electrochemical methods, optical methods are more reliable in low concentration analyte detection using the UV and fluorescence spectra. For instance, glucose oxidase, lactate enzyme, and galactose oxidase have been extensively exploited $[15,19]$. Glucose oxidase (GOx), because of its stability and sensitivity, is practicable in glucose detecting. GOx, based on a well-founded mechanism, is broadly used. During the process, glucose is oxidized by $\mathrm{O}_{2}$ with $\mathrm{GOx}$, generating gluconolactone and $\mathrm{H}_{2} \mathrm{O}_{2}$ as oxidation products [20]. Horseradish peroxidase (HRP) is a kind of practicable enzyme in detecting $\mathrm{H}_{2} \mathrm{O}_{2}$ in the presence of hydrogen donor; the reaction between $\mathrm{HRP}$ and $\mathrm{H}_{2} \mathrm{O}_{2}$ is rapid and specific [21]. In recent years, due to the targeting function, those reactions based on enzymes received a great deal of attention.

Graphene quantum dots (GQDs) and its derivatives have been an area of intense investigation [22-26]. Graphene has been detected and used for years due to its excellent proprieties. When the size of quantum is $<100 \mathrm{~nm}$, the GQDs showed superior properties due to its specific nanometer size effect and specific shape [27,28]. Compared with common carbon dots [29], GQDs has drawn more and more attention these years, owing to its extraordinary properties and functions, including low toxicity [30], high fluorescence activity [31], high solubility [32], unique biocompatibility [33], and long-term resistance to photo-bleaching as well as the feasibility of functionalization at their edges [22,34]. Therefore, many experimental works, including $\mathrm{Pb}^{2+}$ [35], $\mathrm{Cu}^{2+}$ [36], $\mathrm{Hg}^{2+}$ [37], $\mathrm{Mn}^{2+}$ [38], $\mathrm{Ag}^{+}$[39], $\mathrm{Ce}^{4+}$ [40], $\mathrm{DHB}$ [41], glucose [42], and telomere DNA [43] detection are based on its ultrahigh sensitivity and unique electronic and chemical properties.

This study applied a novel Graphene quantum dots (GQDs)-based fluorescent bio-probe for the analysis of glucose value, combining the enzymatic reaction and the quenching effect of GQDs. $\mathrm{H}_{2} \mathrm{O}_{2}$ formed in the glucose oxidation reaction catalyzed by GOx, and upon the addition of HRP and phenol, the phenol oxidized as caused by $\mathrm{H}_{2} \mathrm{O}_{2}$ and HRP [44] to quinone compounds, which could efficiently quench the fluorescence intensity of GQDs [41]. The quenching fluorescence intensity is proportional to the concentration of glucose. Compared with other works, the enzyme-coupled biosensor is much more selective and sensitive for the determination of glucose due to specific characteristics of enzymes. The determination of glucose is based on the combined effect of GOx and HRP, eliminating the common interference factors. The proposed method can pave the way for sensitive detection of analytes that can generate glucose and $\mathrm{H}_{2} \mathrm{O}_{2}$ such as lactate, cholesterol, glycogen, ascorbic acid (AA) and uric acid (UA). By combining GQDs or other fluorescent materials with enzymes, bi-enzymes or multi-enzymes biosensors can be synthesized and utilized for particularly effective analysis.

\section{Results and Discussion}

\subsection{GQDs Characterization}

After the preparation of GQDs, the prepared GQDs were characterized by transmission electron microscopy (TEM). As shown in Figure 1, the diameters of the GQDs are mainly distributed in the range of 10-20 nm. The above-observed properties were consistent with a previous report [25].

\subsection{Detection Principle of the Enzyme-Coupled Biosensor}

The principle of GQD-glucose detection is based on the combination of glucose enzyme reaction and the quenching effect of quinone produced on the GQDs, and the idea of the sensing system is illustrated in Scheme 1. Glucose could cause the quenching effect of GQDs in GOx-HRP-phenol system. Several experiments based on control variate methods have been carried out, the fluorescence emissions were investigated, and the results are shown below. In Figure 2, in the presence of different concentrations of $\mathrm{H}_{2} \mathrm{O}_{2}$, the fluorescence emission of GQDs did not show apparent changes, suggesting that there was no interaction between GQDs and $\mathrm{H}_{2} \mathrm{O}_{2}$. According to a well-founded reaction mentioned above, glucose is oxidized by $\mathrm{O}_{2}$ and GOx and produced $\mathrm{H}_{2} \mathrm{O}_{2}$ and gluconolactone [45]. Thus, the influence of mere addition of glucose and GOx in the GQDs 
sensing system was very slight. Nevertheless, as shown in Figure 3, when glucose, GOx, HRP, phenol were added simultaneously to the GQDs solution, a significant decrease in fluorescence intensity could be observed. For the selectivity of GOx, the level of $\mathrm{H}_{2} \mathrm{O}_{2}$ is hinged on the concentration of glucose. In contrast to the first experiment, upon addition of phenol and HRP, phenol acted as hydrogen donor, which could rapidly and specifically be oxidized by $\mathrm{H}_{2} \mathrm{O}_{2}$ via catalysis by HRP, and generated quinone $[18,46]$. The primary oxidized product, quinone, was a good electron acceptor and efficiently transferred the electron from the excited GQDs [47], causing a considerable quenching effect of the fluorescent system [48]. The spectral results mentioned above provide evidence that, under the same condition, with the presence of GOx, HRP and phenol, glucose can be oxidized; the quinone generated is a suitable quencher in the assay; and the glucose concentration can effectively influence the fluorescence quenching degree of the system.

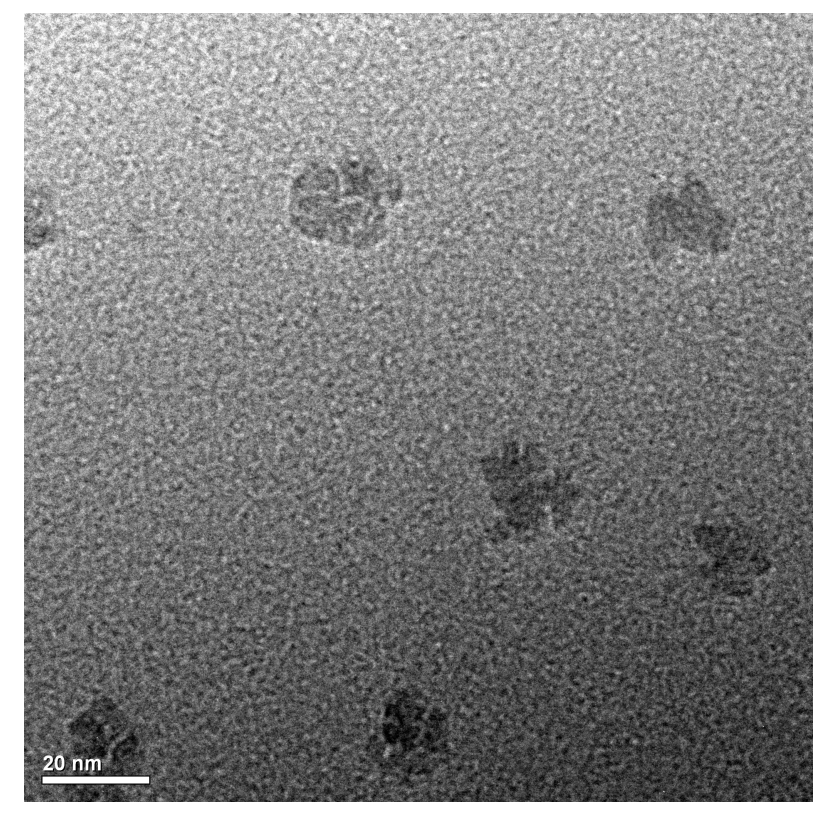

Figure 1. The transmission electron microscopy (TEM) image of GQDs.

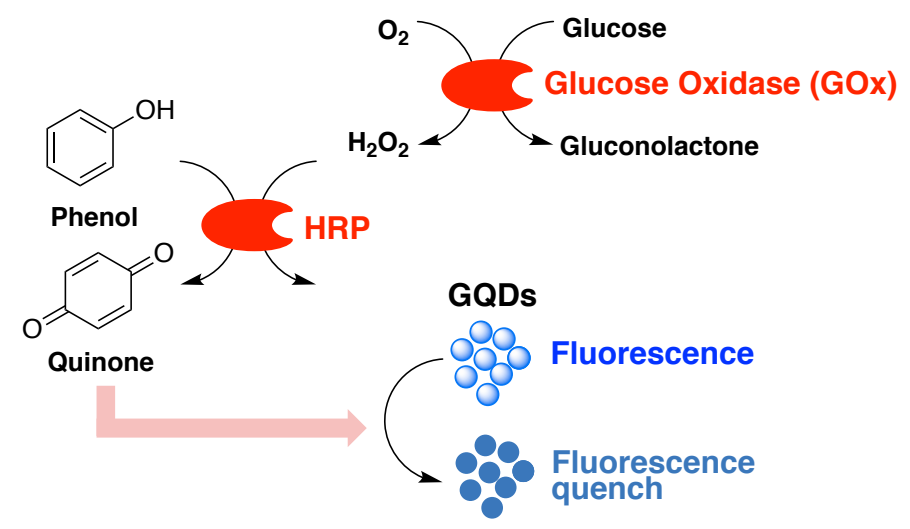

Scheme 1. Schematic representation of sensing strategy to glucose by using glucose oxidase (GOx), horseradish peroxidase (HRP), phenol and GQDs catalyzed reaction. 


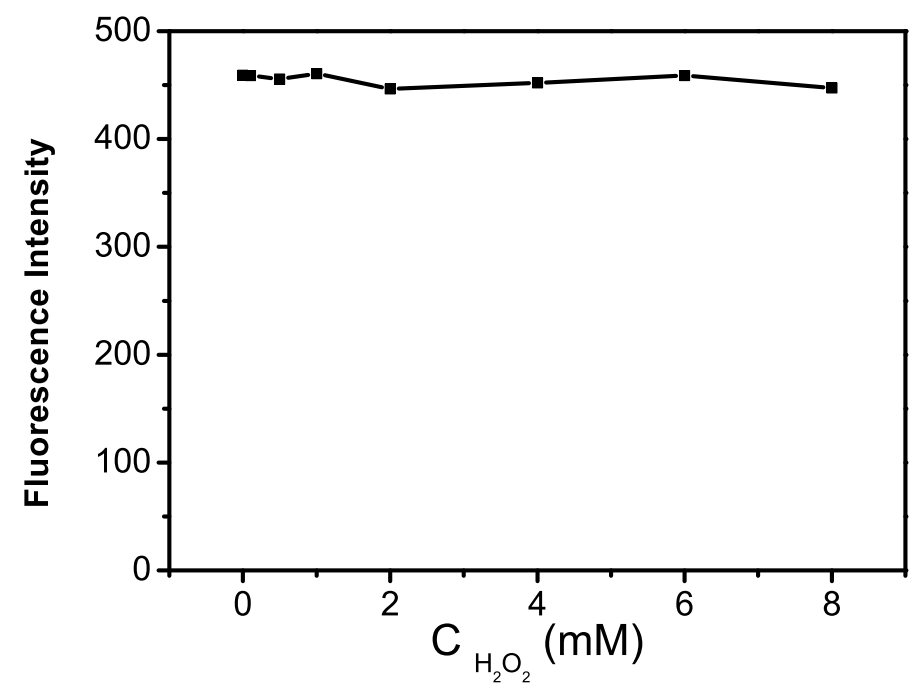

Figure 2. The effect of concentration levels of $\mathrm{H}_{2} \mathrm{O}_{2}$ on the PL intensity of GQDs.

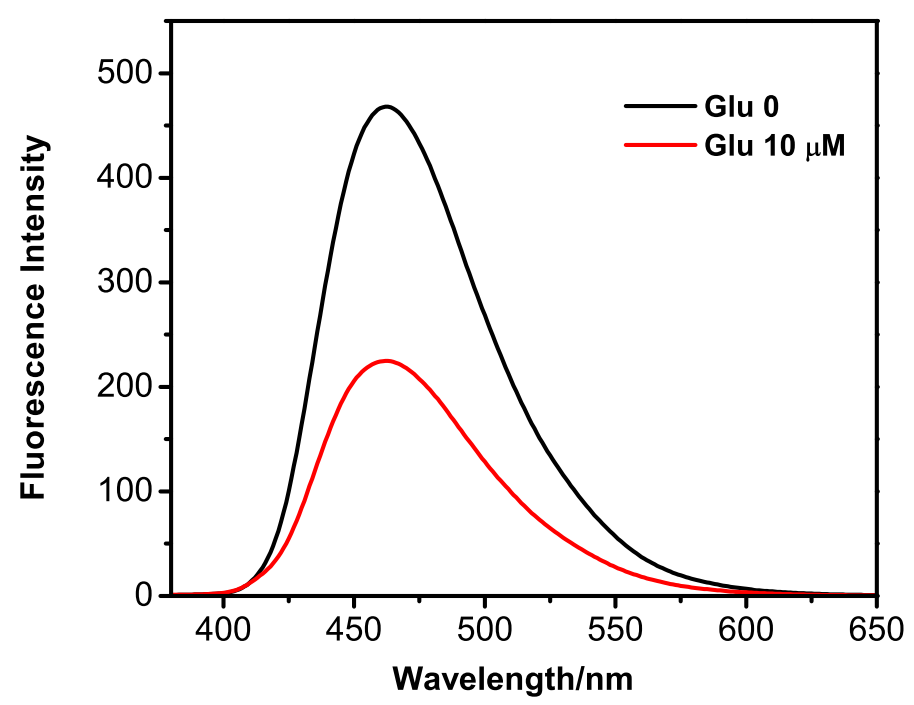

Figure 3. The effect of components of glucose and biosensor on the PL intensity of GQDs: (Black) GQDs-GOx-HRP-phenol; and (Red) GQDs-GOx-HRP-phenol with glucose addition.

\subsection{Optimization of the GQDs-GOx-HRP-Phenol Sensing System}

As the $\mathrm{H}_{2} \mathrm{O}_{2}$ concentration is related to the different addition of the glucose oxidase, to further increase the sensitivity of the system, different concentrations of the glucose oxidase (GOx) were added to the system that includes glucose, GQDs, phenol, and HRP under the same conditions, and the results were investigated by measuring the fluorescence spectra immediately. In Figure 4, it is clear that the quenching effect enhanced with the increasing concentration of GOx until the addition achieved $0.5 \mathrm{mM}$. The fluorescence intensity attained the minimum value at $1.0 \mathrm{mM}$. However, considering the high enzyme cost, $0.5 \mathrm{mM}$ glucose oxidase was a suitable concentration for the following experiments.

To detect the response time of the fluorescence intensity of catalyzed oxidation and GQDs to glucose, the time-dependent fluorescence changes of the system were observed, as shown in Figure 5. The red curve is with the absence of glucose, and the black curve shows the system including glucose. It is obvious that, upon the addition of glucose, fluorescence intensity fell considerably as time increased. After incubation time was longer than $80 \mathrm{~min}$, the fluorescence intensity reached plateau and remained nearly unchanged. The reaction was completed within $80 \mathrm{~min}$. In this study, the incubation time of 80 min was used to establish the optimal condition. 


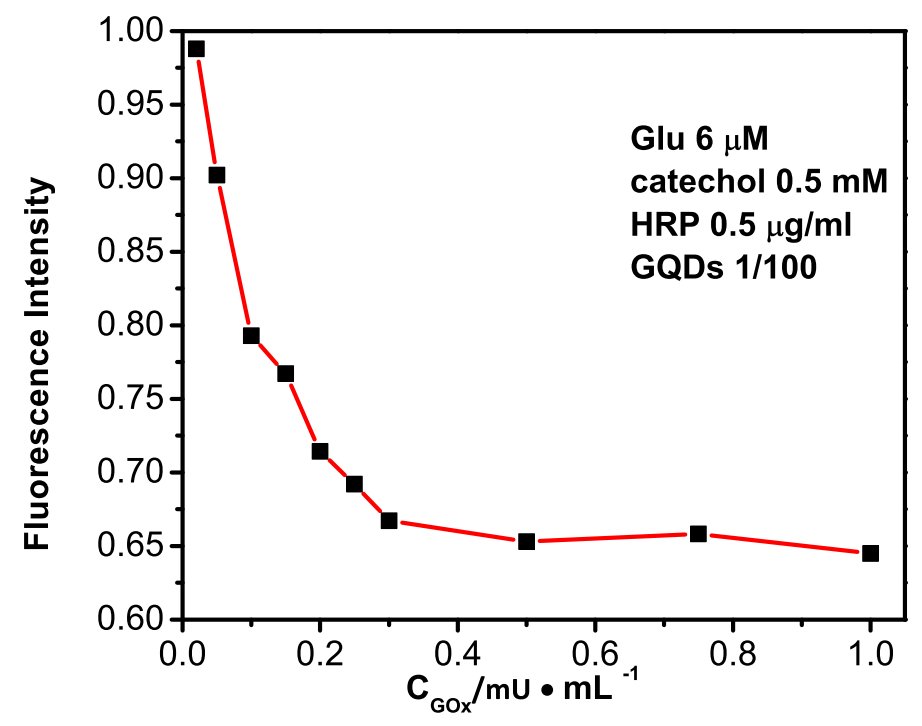

Figure 4. Effect of enzyme concentration on fluorescence intensity.

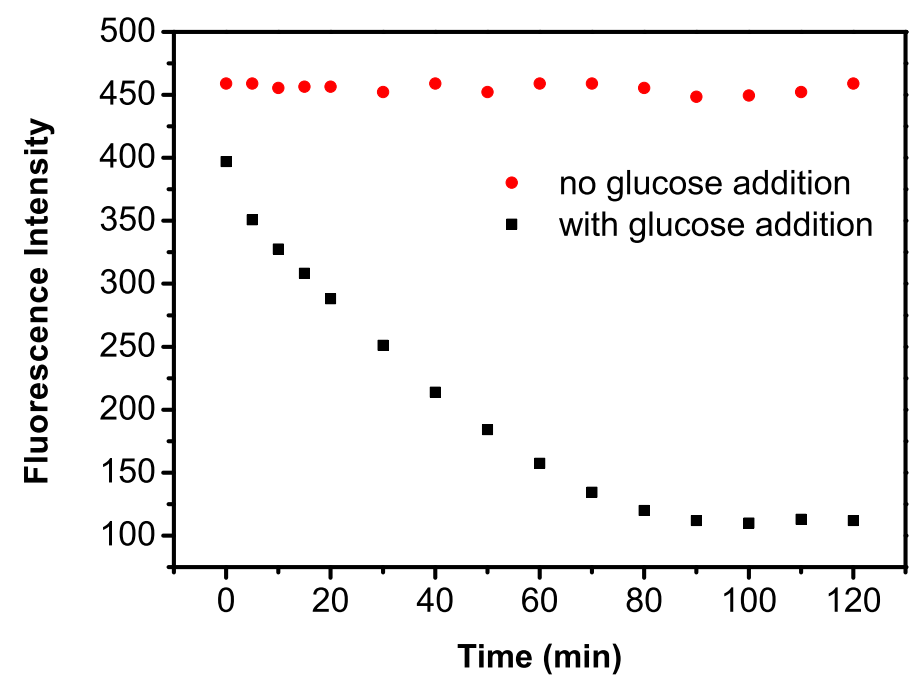

Figure 5. The relationship between fluorescence intensity of the GQDs and the incubation time in the: presence of glucose (Black); and absence of glucose (Red).

\subsection{Detection of Glucose via the GQDs-GOx-HRP-Phenol Sensing System}

To evaluate the sensitivity of this biosensor system to glucose, the experiments proceeded under the optimum conditions discussed above. The fluorescence intensity of GQDs-GOx-HRP-phenol system dropped proportionally upon increasing the concentration of glucose, and the maximum wavelength of the system kept constant (see Figure 6). Adding more glucose generated more quencher through the double enzyme reaction and enhanced the quenching effect on GQDs. As shown in the inset of Figure 6, glucose concentration showed a good linear correlation to $\mathrm{I} / \mathrm{I}_{0}$ in the range of $0.2-10 \mu \mathrm{M}\left(\mathrm{R}^{2}=0.999\right)$ (I and $\mathrm{I}_{0}$ were the fluorescence intensities of the GQDs-HRP-phenol system in the presence and absence of glucose, respectively). The regression equation for this method can be described as $\mathrm{I} / \mathrm{I}_{0}=0.991-0.0896 \mathrm{C}_{\text {glucose }}(\mu \mathrm{M})$ and the corresponding detection limit (LOD) was $0.08 \mu \mathrm{M}$, which was calculated as $3 \sigma / \mathrm{s}$. The LOD is much lower than most previous reported colorimetric, electrochemical and fluorescent sensors for glucose detection (Table 1). 


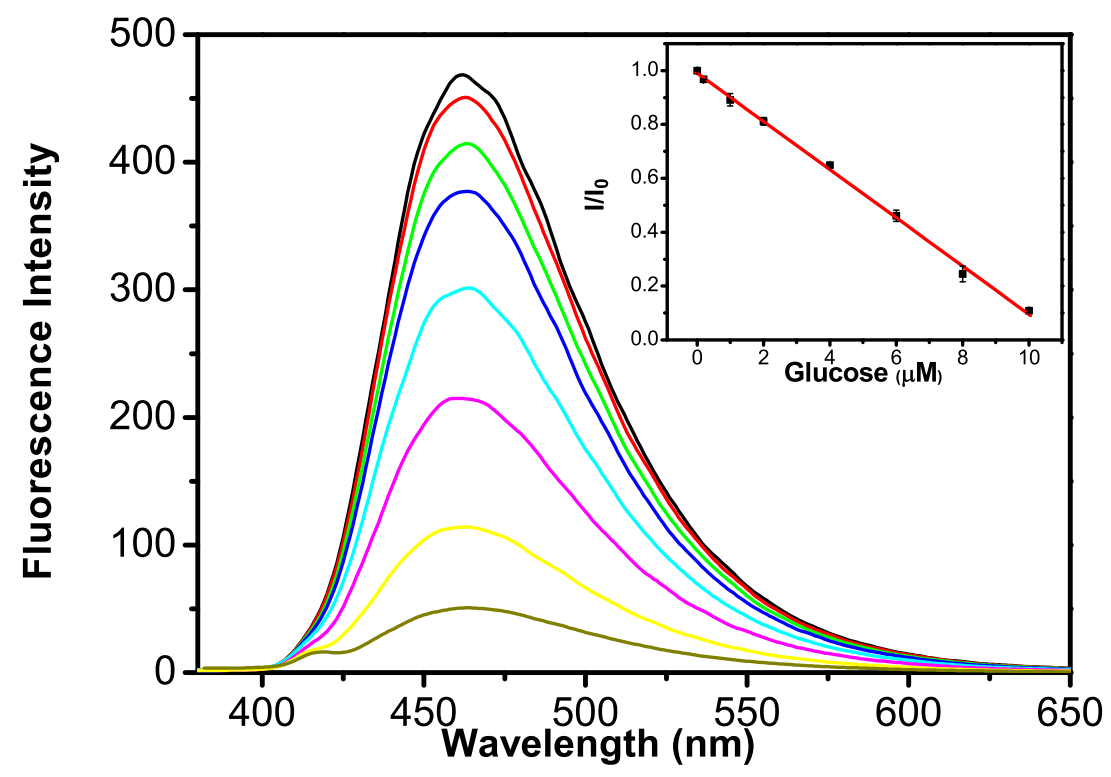

Figure 6. Fluorescence emission spectra of different concentrations of glucose. 0 (black), 0.2 (red), 1.0 (green), 2.0 (blue), 4.0 (cyan), 6.0 (magenta), 9.0 (yellow), 10 (dark yellow) $\mu \mathrm{mol} / \mathrm{L}$, respectively. Inset is the linear calibration of the fluorescence intensity ratio of $\mathrm{I} / \mathrm{I}_{0}$ and the concentration of glucose.

Table 1. Comparison of different methods for the determination of glucose.

\begin{tabular}{ccccc}
\hline Method & System & Linear Range $(\mu \mathrm{M})$ & LOD $(\mu \mathrm{M})$ & Reference \\
\hline Colorimetry & Graphene oxide/GOx/TMB & $1-20$ & 1 & {$[49]$} \\
Colorimetry & Au-PtNCs/GOx/TMB & $5-55$ & 2.4 & {$[50]$} \\
Electrochemistry & Graphene quantum dots/GOx & $5-1270$ & 1.73 & {$[51]$} \\
Fluorometry & Hemin-functionalized GQDs/GOx & $9-300$ & 0.1 & {$[42]$} \\
Fluorometry & Si quantum dots/GOx & $5-650$ & 0.68 & {$[52]$} \\
Fluorometry & C-dots/AgNPs/GOx & $2-100$ & 1.39 & {$[53]$} \\
Fluorometry & Hb-AuNCs/GOx & $0.5-1000$ & 1.65 & {$[54]$} \\
Fluorometry & TA/Fe-Phen-CFs & $0.5-200$ & 0.19 & {$[55]$} \\
Fluorometry & Graphene quantum dots/GOx/HRP/phenol & $0.2-10$ & 0.08 & This paper \\
\hline
\end{tabular}

\subsection{Selectivity of the GQDs-GOx-HRP-Phenol Sensing System for Detecting Glucose}

To test whether this GQDs-GOx-HRP-phenol sensing system is selective toward glucose, the fluorescence changes were measured upon the addition of eight potential substances that commonly exist in the human body,: $\mathrm{Mg}^{2+}, \mathrm{Zn}^{2+}, \mathrm{Ca}^{2+}, \mathrm{Na}^{+}, \mathrm{K}^{+}$, pepsin, BSA, GSH, and Cys. As the results in Figure 7 show, the fluorescence intensity observed of the GQDs-GOx-HRP-phenol sensing system did not change obviously over the high concentration of interference, which suggests that the present approach has excellent selectivity in detecting glucose with various kinds of substances. The high selectivity can be attributed to the specificity between enzyme and substrate: GOx is selective toward glucose and $\mathrm{HRP}$ is selective toward $\mathrm{H}_{2} \mathrm{O}_{2}$, while other interferents cannot bind the enzyme and the biosensor has strong anti-interference ability. 


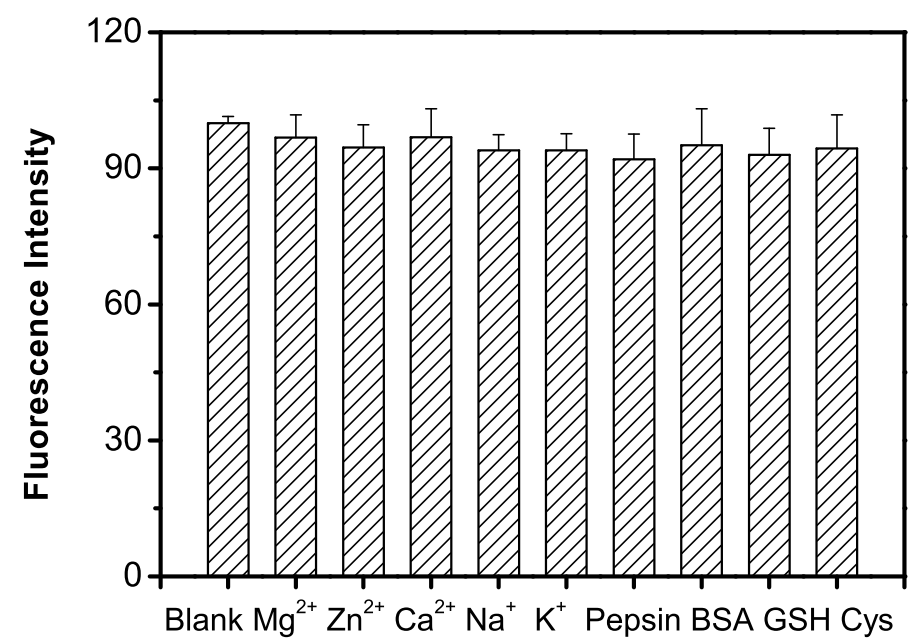

Figure 7. Effect of glucose concentration on $\mathrm{I} / \mathrm{I}_{0}$ in the presence of potential interferents.

\subsection{Application of Assaying Glucose Concentration in Human Serum Samples}

To evaluate the applicability of the GQDs-GOx-HRP-phenol sensing system in the biological environment, we measured the fluorescence intensities of human serum samples spiked with glucose, and calculated the glucose concentration, recoveries and relative standard deviations (RSDs) for every system. The measurements of two samples were repeated three times and the results obtained from three separate experiments showed good repeatability, as listed in Table 2. The samples spiked with different concentrations showed good recoveries in the range of $98.5-102.0 \%$, RSDs were less than $\pm 5 \%$, and the results were consistent with those obtained by medical methods. Therefore, we found that the enzyme-coupled biosensor is reliable and comparable in the determination of glucose in the biological environment.

Table 2. Glucose determination in dilute serum samples $(n=3)$.

\begin{tabular}{lcccc}
\hline Samples & Added Glucose $(\mu \mathbf{M})$ & Measured $(\mu \mathbf{M})$ & Recovery (\%) & RSD (\%) \\
\hline Serum 1 & 2 & 1.97 & 98.5 & 3.94 \\
Serum 2 & 5 & 5.11 & 102.0 & 2.44 \\
\hline
\end{tabular}

\section{Materials and Methods}

\subsection{Chemicals and Reagents}

In this work, all reagents used were of analytical grade without further purification. Ultrapure water used throughout all experiments was purchased from Hangzhou Wahaha Group Co. Ltd., (Hangzhou, China). Catechol, $\mathrm{NaOH}, \mathrm{Na}_{2} \mathrm{HPO}_{4}, \mathrm{NaH}_{2} \mathrm{PO}_{4}$, citric acid (CA) and $\mathrm{H}_{2} \mathrm{O}_{2}$ were acquired from Beijing Chemical Works (Beijing, China). Horseradish peroxidase (HRP), Pepsin, Bovine serum albumin (BSA), cysteine (Cys), glutathione (GSH), Ascorbic acid, Glutathione and amino acids were obtained from Beijing Dingguo Biotechnology (Beijing, China). Glucose and glucose oxidase (Worthington, Shanghai, China) were purchased from Sangon Biotech (Shanghai, China). Human serum samples were obtained from the healthy volunteers at the China Japan Union Hospital (Changchun, China) and the samples were prepared and diluted.

\subsection{Instrumentation}

Transmission electron microscopy (TEM) images were obtained with a JEM2100F high-resolution transmission electron microscope (JEOL, Tokyo, Japan) at an acceleration voltage of $200 \mathrm{kV}$. All measurements of fluorescence were performed under a $360 \mathrm{~nm}$ excitation wavelength. All samples 
were decanted in a standard $1 \mathrm{~cm}$ pathway spectrophotometric cuvette. The fluorescence signal corresponded the maximum emission of GQDs well at $466 \mathrm{~nm}$. Records were obtained on a Shimadzu RF-5301 spectrometer (Shimadzu, Kyoto, Japan). Optical measurements were done in aqueous solutions at room temperature.

\subsection{Synthesis of GQDs}

The GQDs was synthesized in accordance with a method described in previous reports [41,42]. Briefly, $2.0 \mathrm{~g}$ citric acid is heated in a $5 \mathrm{~mL}$ beaker at approximately $260{ }^{\circ} \mathrm{C}$ for $17 \mathrm{~min}$ to produce molten CA. The light yellow liquid was then introduced into $100 \mathrm{~mL}$ of $250 \mathrm{mM} \mathrm{NaOH}$ solution with vigorous stirring, neutralizing at a $\mathrm{pH}$ of 7.0. The obtained GQDs stored at $4{ }^{\circ} \mathrm{C}$ for further application.

\subsection{Optimization of the Sensing System}

For $\mathrm{H}_{2} \mathrm{O}_{2}$ detection, $\mathrm{H}_{2} \mathrm{O}_{2}$ with different concentrations were freshly prepared and added with $0.5 \mu \mathrm{g} / \mathrm{mL}$ HRP, $0.05 \mathrm{mM}$ catechol and 10\% GQDs followed. All samples were incubated at $37^{\circ} \mathrm{C}$ for $80 \mathrm{~min}$.

For glucose concentration effect analysis, $10 \mu \mathrm{mol} / \mathrm{L}$ glucose was added into the system with $5 \mu \mathrm{mol} / \mathrm{L}$ GQDs, $0.5 \mu \mathrm{g} / \mathrm{mL}$ HRP, $0.05 \mathrm{mM}$ catechol, and $0.05 \mathrm{mM}$ GOx. All samples were incubated at $37^{\circ} \mathrm{C}$ for $80 \mathrm{~min}$.

For enzyme concentration effect analysis, fluorescence intensities were detected in the system of $6 \mu \mathrm{M}$ glucose, $0.05 \mathrm{mM}$ catechol, $0.5 \mu \mathrm{g} / \mathrm{mL}$ HRP and 1\% GQDs. All samples were incubated at $37^{\circ} \mathrm{C}$ for $80 \mathrm{~min}$.

For incubation time detection, glucose was added to the system within $5 \mu \mathrm{mol} / \mathrm{L}$ GQDs, $0.5 \mu \mathrm{g} / \mathrm{mL}$ HRP, $0.05 \mathrm{mM}$ catechol, $10 \mu \mathrm{mol} / \mathrm{L}$ glucose and $0.05 \mathrm{mM} \mathrm{GOx}$, and samples were incubated at $37^{\circ} \mathrm{C}$ for different periods.

All ingredients were blended well under the optimal condition before the fluorescence signal of the mixture was recorded with a luminescence spectrometer.

\subsection{Assay of Glucose}

The calibration curve of the approach toward glucose was carried out under optimal conditions. Glucose solutions with certain concentrations $(0,0.2,1.0,2.0,4.0,6.0,9.0$, and $10 \mu \mathrm{mol} / \mathrm{L}$, respectively) were added into the system with $0.5 \mu \mathrm{g} / \mathrm{mL}$ HRP, $0.05 \mathrm{mM}$ catechol, $0.05 \mathrm{mM}$ GOx and $5.0 \mu \mathrm{mol} / \mathrm{L}$ GQDs, respectively. All samples were then diluted to $1.00 \mathrm{~mL}$ with PBS (pH 7.4) buffer. The pre-samples $(1.0 \mathrm{~mL})$ were shaken evenly before incubated at $37^{\circ} \mathrm{C}$ for about $80 \mathrm{~min}$. Then, fluorescence spectra were measured by luminescence spectrometer.

\subsection{Interference Study}

To evaluate the system selectivity toward glucose detection, $500 \mu \mathrm{mol}$ solution of other common substances that commonly exist in the human body- $\mathrm{Mg}^{2+}, \mathrm{Zn}^{2+}, \mathrm{Ca}^{2+}, \mathrm{Na}^{+}, \mathrm{K}^{+}$, pepsin, BSA, GSH, and Cys - were prepared with $0.5 \mu \mathrm{g} / \mathrm{mL}$ HRP, $0.05 \mathrm{mM}$ catechol, $0.05 \mathrm{mM} \mathrm{GOx}$ and $5.0 \mu \mathrm{mol} / \mathrm{L}$ GQDs in PBS buffer (pH 7.4), respectively.

\subsection{Fluorescence Detection of Glucose in Human Blood Serum}

To further test detection in real biological samples, two human blood samples, obtained by venipuncture from drug-free subjects, were used to assess the practicability of the GQDs-double enzyme system. After centrifugation at 10,000 rpm at room temperature for $10 \mathrm{~min}$, the samples offering the best analytical performance for the assay were determined. The supernatant was stored under $-20^{\circ} \mathrm{C}$ as a stock solution before the assay. The reaction serum samples were spiked with various concentrations of glucose and phenol-GQDs-double enzyme system before fluorescence detection. 
For the determination of total glucose, human serum samples were prepared and diluted without any pre-treatment, except for a 100 times dilution. The fluorescence spectra for spiked serum samples and serum samples were recorded. By drawing the linear dependence relation of fluorescence intensity and the glucose level, quantification of glucose in the samples could be calculated. The measurement of two samples were repeated three times.

\section{Conclusions}

In conclusion, a simple and sensitive approach for glucose determination based upon the combination between specific enzymatic reaction and quenching effect of GQDs is reported. The reaction between the glucose and GQDs was accomplished by the addition of GOx, HRP and phenol. Glucose was oxidized by GOx; the formed $\mathrm{H}_{2} \mathrm{O}_{2}$ oxidized phenol via the catalysis by HRP. The oxidation product, quinone, caused the conspicuous quenching effect on GQDs due to efficient electron transfer from GQDs to quinone. The analysis results suggest the quenching degree was proportional to glucose concentration, which means the proposed approach could be successfully applied for the quantization of the glucose.

The bio-probe shows a high sensitivity ascribed to the ultrahigh optical properties of GQDs, and achieves high selectivity towards glucose attributable to the specificity and the unique affinity of the enzyme coupling method. The present approach is applicable for detecting glucose in human serum samples and have the potentiality to be extended to other systems. The present approach provided a pathway for the determination of the substance, which can generate glucose ${ }^{\circ} \mathrm{H}_{2} \mathrm{O}_{2}$. By combining fluorescent materials with the enzyme-coupled system, selective optical methods can have a more comprehensive application in future development.

Author Contributions: H.Z. and Z.L. conceived and designed the experiments; B.W. performed the experiments and analyzed data; J.S. wrote the paper and visualized data; B.W. and Z.L. revised the paper; and H.Z. and Y.H. supervised the work. All authors read and approved the final manuscript.

Acknowledgments: This work was financially supported by the National Natural Science Foundation of China (31772058), Natural Science Foundation of Jilin Province (20160520127JH), China Postdoctoral Science Foundation (2016T90260 and 2013M541309), and Fundamental Research Funds for the Central Universities. This research received no external funding.

Conflicts of Interest: The authors declare no conflict of interest.

$\begin{array}{ll}\text { Abbreviations } \\ \text { GQDs } & \text { Graphene quantum dots } \\ \mathrm{HRP} & \text { horseradish peroxidase } \\ \mathrm{GOx} & \text { glucose oxidase } \\ \mathrm{H}_{2} \mathrm{O}_{2} & \text { hydrogen peroxide }\end{array}$

\section{References}

1. Matz, K.; Keresztes, K.; Tatschl, C.; Nowotny, M.; Dachenhausen, A.; Brainin, M.; Tuomilehto, J. Disorders of glucose metabolism in acute stroke patients: An underrecognized problem. Diabetes Care 2006, 29, $792-797$. [CrossRef] [PubMed]

2. Barzilay, J.I.; Spiekerman, C.F.; Kuller, L.H.; Burke, G.L.; Bittner, V.; Gottdiener, J.S.; Brancati, F.L.; Orchard, T.J.; O'Leary, D.H.; Savage, P.J. Prevalence of clinical and isolated subclinical cardiovascular disease in older adults with glucose disorders-The Cardiovascular Health Study. Diabetes Care 2001, 24, 1233-1239. [CrossRef] [PubMed]

3. Pickup, J.C.; Zhi, Z.L.; Khan, F.; Saxl, T.; Birch, D.J.S. Nanomedicine and its potential in diabetes research and practice. Diabetes Metab. Res. Rev. 2008, 24, 604-610. [CrossRef] [PubMed]

4. Chowdhury, H.H.; Kreft, M.; Jensen, J.; Zorec, R. Insulin Induces an Increase in Cytosolic Glucose Levels in 3T3-L1 Cells with Inhibited Glycogen Synthase Activation. Int. J. Mol. Sci. 2014, 15, 17827-17837. [CrossRef] [PubMed] 
5. Arvand, M.; Hemmati, S. Magnetic nanoparticles embedded with graphene quantum dots and multiwalled carbon nanotubes as a sensing platform for electrochemical detection of progesterone. Int. J. Mol. Sci. 2017, 238, 346-356. [CrossRef]

6. Shiddiky, M.J.A.; Rauf, S.; Kithva, P.H.; Trau, M. Graphene/quantum dot bionanoconjugates as signal amplifiers in stripping voltammetric detection of EpCAM biomarkers. Biosens. Bioelectron. 2012, 35, $251-257$. [CrossRef] [PubMed]

7. Su, L.; Feng, J.; Zhou, X.; Ren, C.; Li, H.; Chen, X. Colorimetric Detection of Urine Glucose Based ZnFe2O4 Magnetic Nanoparticles. Anal. Chem. 2012, 84, 5753-5758. [CrossRef] [PubMed]

8. Xia, X.D.; Long, Y.F.; Wang, J.X. Glucose oxidase-functionalized fluorescent gold nanoclusters as probes for glucose. Anal. Chim. Acta 2013, 772, 81-86. [CrossRef] [PubMed]

9. Jin, L.; Shang, L.; Guo, S.; Fang, Y.; Wen, D.; Wang, L.; Yin, J.; Dong, S. Biomolecule-stabilized Au nanoclusters as a fluorescence probe for sensitive detection of glucose. Biosens. Bioelectron. 2011, 26, 1965-1969. [CrossRef] [PubMed]

10. Sricharoen, P.; Limchoowong, N.; Areerob, Y.; Nuengmatcha, P.; Techawongstien, S.; Chanthai, S. $\mathrm{Fe} 3 \mathrm{O} 4 /$ hydroxyapatite/graphene quantum dots as a novel nano-sorbent for preconcentration of copper residue in Thai food ingredients: Optimization of ultrasound-assisted magnetic solid phase extraction. Ultrason. Sonochem. 2017, 37, 83-93. [CrossRef] [PubMed]

11. Zhang, W.L.H.; Zhang, L.L.; Gao, H.L.; Yang, W.Y.; Wang, S.; Xing, L.L.; Xue, X.Y. Self-Powered Implantable Skin-Like Glucometer for Real-Time Detection of Blood Glucose Level In Vivo. Nano-Micro Lett. 2018, 10, 32. [CrossRef]

12. Newman, J.D.; Turner, A.P.F. Home blood glucose biosensors: A commercial perspective. Biosens. Bioelectron. 2005, 20, 2435-2453. [CrossRef] [PubMed]

13. Steiner, M.S.; Duerkop, A.; Wolfbeis, O.S. Optical methods for sensing glucose. Chem. Soc. Rev. 2011, 40, 4805-4839. [CrossRef] [PubMed]

14. Huang, X.Y.; Lan, T.; Zhang, B.C.; Ren, J.C. Gold nanoparticle-enzyme conjugates based FRET for highly sensitive determination of hydrogen peroxide, glucose and uric acid using tyramide reaction. Analyst 2012, 137, 3659-3666. [CrossRef] [PubMed]

15. Jacobs, C.B.; Peairs, M.J.; Venton, B.J. Review: Carbon nanotube based electrochemical sensors for biomolecules. Anal. Chim. Acta 2010, 662, 105-127. [CrossRef] [PubMed]

16. Besteman, K.; Lee, J.O.; Wiertz, F.G.M.; Heering, H.A.; Dekker, C. Enzyme-coated carbon nanotubes as single-molecule biosensors. Nano Lett. 2003, 3, 727-730. [CrossRef]

17. Wang, Y.J.; Xin, B.J.; Duan, X.R.; Xing, G.W.; Wang, S. Assembly of Anionic Conjugated Polymer with 6-O-Modified PNP-beta-Galactoside for Fluorescence Logic-signal-based Multiplex Detections of Enzymes. Macromol. Rapid. Commun. 2010, 31, 1473-1478. [CrossRef] [PubMed]

18. Azmi, N.E.; Ramli, N.I.; Abdullah, J.; Hamid, M.A.A.; Sidek, H.; Abd Rahman, S.; Ariffin, N.; Yusof, N.A. A simple and sensitive fluorescence based biosensor for the determination of uric acid using $\mathrm{H} 2 \mathrm{O} 2$-sensitive quantum dots/dual enzymes. Biosens. Bioelectron. 2015, 67, 129-133. [CrossRef] [PubMed]

19. Uusitalo, L.M.; Hempel, N. Recent Advances in Intracellular and In Vivo ROS Sensing: Focus on Nanoparticle and Nanotube Applications. Int. J. Mol. Sci. 2012, 13, 10660-10679. [CrossRef] [PubMed]

20. McQuade, D.T.; Pullen, A.E.; Swager, T.M. Conjugated polymer-based chemical sensors. Chem. Rev. 2000, 100, 2537-2574. [CrossRef] [PubMed]

21. Mohanty, J.G.; Jaffe, J.S.; Schulman, E.S.; Raible, D.G. A highly sensitive fluorescent micro-assay of $\mathrm{H}_{2} \mathrm{O}_{2}$ release from activated human leukocytes using a dihydroxyphenoxazine derivative. J. Immunol. Methods 1997, 202, 133-141. [CrossRef]

22. Geim, A.K. Graphene: Status and Prospects. Science 2009, 324, 1530-1534. [CrossRef] [PubMed]

23. Forsyth, R.; Devadoss, A.; Guy, O.J. Graphene Field Effect Transistors for Biomedical Applications: Current Status and Future Prospects. Diagnostics 2017, 7, 45. [CrossRef] [PubMed]

24. Najafabadi, A.T. Emerging applications of graphene and its derivatives in carbon capture and conversion: Current status and future prospects. Renew. Sustain. Energy Rev. 2015, 41, 1515-1545. [CrossRef]

25. Bacon, M.; Bradley, S.J.; Nann, T. Graphene Quantum Dots. Part. Part. Syst. Charact. 2014, 31, 415-428. [CrossRef]

26. Dai, H.J. Carbon nanotubes: Opportunities and challenges. Surf. Sci. 2017, 500, 218-241. [CrossRef] 
27. Ponomarenko, L.A.; Schedin, F.; Katsnelson, M.I.; Yang, R.; Hill, E.; Novoselov, K.S.; Geim, A.K. Chaotic dirac billiard in graphene quantum dots. Science 2008, 320, 356-358. [CrossRef] [PubMed]

28. Wang, L.; Wang, Y.L.; Xu, T.; Liao, H.B.; Yao, C.J.; Liu, Y.; Li, Z.; Chen, Z.W.; Pan, D.Y.; Sun, L.T.; et al. Gram-scale synthesis of single-crystalline graphene quantum dots with superior optical properties. Nat. Commun. 2014, 5, 5357. [CrossRef] [PubMed]

29. Samareh, J.A.; Siochi, E.J. Systems analysis of carbon nanotubes: Opportunities and challenges for space applications. Nanotechnology 2017, 28, 372001. [CrossRef] [PubMed]

30. Chong, Y.; Ma, Y.F.; Shen, H.; Tu, X.L.; Zhou, X.; Xu, J.Y.; Dai, J.W.; Fan, S.J.; Zhang, Z.J. The in vitro and in vivo toxicity of graphene quantum dots. Biomaterials 2014, 35, 5041-5048. [CrossRef] [PubMed]

31. Qian, Z.S.; Shan, X.Y.; Chai, L.J.; Chen, J.R.; Peng, H. A fluorescent nanosensor based on graphene quantum dots-aptamer probe and graphene oxide platform for detection of lead (II) ion. Biosens. Bioelectron. 2015, 68, 225-231. [CrossRef] [PubMed]

32. Vasilescu, I.; Eremia, S.A.V.; Kusko, M.; Radoi, A.; Vasile, E.; Radu, G.L. Molybdenum disulphide and graphene quantum dots as electrode modifiers for laccase biosensor. Biosens. Bioelectron. 2016, 75, 232-237. [CrossRef] [PubMed]

33. Shang, W.H.; Zhang, X.Y.; Zhang, M.; Fan, Z.T.; Sun, Y.T.; Han, M.; Fan, L.Z. The uptake mechanism and biocompatibility of graphene quantum dots with human neural stem cells. Nanoscale 2014, 6, 5799-5806. [CrossRef] [PubMed]

34. Fan, Z.T.; Zhou, S.X.; Garcia, C.; Fan, L.Z.; Zhou, J.B. pH-Responsive fluorescent graphene quantum dots for fluorescence-guided cancer surgery and diagnosis. Nanoscale 2017, 9, 4928-4933. [CrossRef] [PubMed]

35. Qi, Y.X.; Zhang, M.; Fu, Q.Q.; Liu, R.; Shi, G.Y. Highly sensitive and selective fluorescent detection of cerebral lead(II) based on graphene quantum dot conjugates. Chem. Commun. 2013, 49, 10599-10601. [CrossRef] [PubMed]

36. Na, W.D.; Qu, Z.Y.; Chen, X.Q.; Su, X.G. A turn-on fluorescent probe for sensitive detection of sulfide anions and ascorbic acid by using sulfanilic acid and glutathione functionalized graphene quantum dots. Sens. Actuators B 2018, 256, 48-54. [CrossRef]

37. Wang, B.J.; Zhuo, S.J.; Chen, L.Y.; Zhang, Y.J. Fluorescent graphene quantum dot nanoprobes for the sensitive and selective detection of mercury ions. Spectrochim. Acta Part A 2014, 131, 384-387. [CrossRef] [PubMed]

38. Yang, L.; Qin, A.M.; Chen, S.P.; Liao, L.; Qin, J.K.; Zhang, K.Y. Manganese(II) enhanced fluorescent nitrogen-doped graphene quantum dots: A facile and efficient synthesis and their applications for bioimaging and detection of $\mathrm{Hg} 2+$ ions. RSC Adv. 2018, 8, 5902-5911. [CrossRef]

39. Zhao, X.E.; Lei, C.H.; Gao, Y.; Gao, H.; Zhu, S.Y.; Yang, X.; You, J.M.; Wang, H. A ratiometric fluorescent nanosensor for the detection of silver ions using graphene quantum dots. Sens. Actuators B 2017, 253, $239-246$. [CrossRef]

40. Liu, R.; Yang, R.; Qu, C.J.; Mao, H.C.; Hu, Y.; Li, J.J.; Qu, L.B. Synthesis of glycine-functionalized graphene quantum dots as highly sensitive and selective fluorescent sensor of ascorbic acid in human serum. Sens. Actuators B 2017, 241, 644-651. [CrossRef]

41. Li, Y.X.; Huang, H.; Ma, Y.H.; Tong, J. Highly sensitive fluorescent detection of dihydroxybenzene based on graphene quantum dots. Sens. Actuators B 2014, 205, 227-233. [CrossRef]

42. He, Y.; Wang, X.; Sun, J.; Jiao, S.; Chen, H.; Gao, F.; Wang, L. Fluorescent blood glucose monitor by hemin-functionalized graphene quantum dots based sensing system. Anal. Chim. Acta 2014, 810, 71-78. [CrossRef] [PubMed]

43. Huang, S.; Wang, L.M.; Huang, C.S.; Su, W.; Xiao, Q. Label-free and ratiometric fluorescent nanosensor based on amino-functionalized graphene quantum dots coupling catalytic G-quadruplex/hemin DNAzyme for ultrasensitive recognition of human telomere DNA. Sens. Actuators B 2017, 245, 648-655. [CrossRef]

44. Minisci, F.; Citterio, A.; Vismara, E.; Fontana, F.; Debernardinis, S.; Correale, M. Facile and Convenient Syntheses of Quinones from Phenols. J. Org. Chem. 1989, 54, 728-731. [CrossRef]

45. Huggett, A.S.G.; Nixoh, D.A. Use of glucose oxidase, peroxidase, and o-dianisidine in determination of blood and urinary glucose. Lancet 1957, 273, 368. [CrossRef]

46. Yuan, J.; Guo, W.; Wang, E. Utilizing a CdTe quantum dots-enzyme hybrid system for the determination of both phenolic compounds and hydrogen peroxide. Anal. Chem. 2008, 80, 1141-1145. [CrossRef] [PubMed] 
47. Li, Z.; Sun, R.L.; Ni, Y.N.; Kokot, S. A novel fluorescent probe involving a graphene quantum dot-enzyme hybrid system for the analysis of hydroquinone in the presence of toxic resorcinol and catechol. Anal. Methods 2014, 6, 7420-7425. [CrossRef]

48. Cai, N.; Tan, L.; Li, Y.; Xia, T.; Hu, T.; Su, X. Biosensing platform for the detection of uric acid based on graphene quantum dots and Gquadruplex/hemin DNAzyme. Anal. Chim. Acta 2017, 965, 96. [CrossRef] [PubMed]

49. Song, Y.J.; Qu, K.G.; Zhao, C.; Ren, J.S.; Qu, X.G. Graphene Oxide: Intrinsic Peroxidase Catalytic Activity and Its Application to Glucose Detection. Adv. Mater. 2010, 22, 2206-2210. [CrossRef] [PubMed]

50. Feng, J.Y.; Huang, P.C.; Wu, F.Y. Gold-platinum bimetallic nanoclusters with enhanced peroxidase-like activity and their integrated agarose hydrogel-based sensing platform for the colorimetric analysis of glucose levels in serum. Analys 2017, 142, 4106-4115. [CrossRef] [PubMed]

51. Razmi, H.; Mohammad-Rezaei, R. Graphene quantum dots as a new substrate for immobilization and direct electrochemistry of glucose oxidase: Application to sensitive glucose determination. Biosens. Bioelectron. 2013, 41, 498-504. [CrossRef] [PubMed]

52. Yi, Y.H.; Deng, J.H.; Zhang, Y.Y.; Li, H.T.; Yao, S.Z. Label-free Si quantum dots as photoluminescence probes for glucose detection. Chem. Commun. 2013, 49, 612-614. [CrossRef] [PubMed]

53. Ma, J.L.; Yin, B.C.; Wu, X.; Ye, B.C. Simple and Cost-Effective Glucose Detection Based on Carbon Nanodots Supported on Silver Nanoparticles. Anal. Chem. 2017, 89, 1323-1328. [CrossRef] [PubMed]

54. Molaabasi, F.; Hosseinkhani, S.; Moosavi-Movahedi, A.A.; Shamsipur, M. Hydrogen peroxide sensitive hemoglobin-capped gold nanoclusters as a fluorescence enhancing sensor for the label-free detection of glucose. RSC Adv. 2015, 5, 33123-33135. [CrossRef]

55. Zhang, R.Z.; He, S.J.; Zhang, C.M.; Chen, W. Three-dimensional Fe- and N-incorporated carbon structures as peroxidase mimics for fluorescence detection of hydrogen peroxide and glucose. J. Phys. Chem. B 2015, 3, 4146-4154. [CrossRef]

(C) 2018 by the authors. Licensee MDPI, Basel, Switzerland. This article is an open access article distributed under the terms and conditions of the Creative Commons Attribution (CC BY) license (http://creativecommons.org/licenses/by/4.0/). 